\title{
Cancer care in the UK: we need to be more ambitious
}

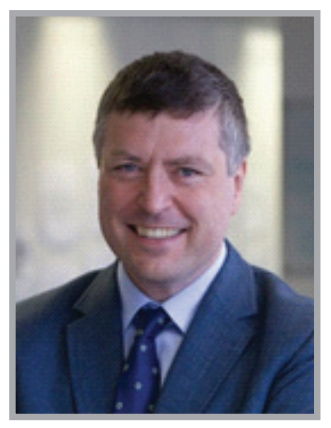

Ciarán Devane* speaks to Francesca Lake, Managing Commissioning Editor: Ciarán Devane is the outgoing Chief Executive of Macmillan Cancer Support. Educated at University College Dublin (Ireland), he holds a degree in biochemical engineering. He also holds a Master's degree in international policy from George Washington University (DC, USA). Ciarán is a trustee of the National Council for Voluntary Organisations sits on the advisory council of the Cicely Saunders Institute, an institute for research into palliative care (London, UK). Since January 2012, he has also been a Non-Executive Director of the National Health Service England.

Q Can you tell us a little about your career, \& what led you to where you are to day? I'm a chemical engineer, and joined what was Imperial Chemical Industries on Teesside (UK) back in 1984, 30 years ago! I spent a number of years there, which was great training, as it invested a lot in its people. After approximately 9 years, I moved on to management consulting at Gemini Consulting in London, UK). This background formed a good combination - you have this very development-focused, multinational early career, and then Gemini in London, at the time one of the great management consulting practices doing work across a whole bunch of industries. You couldn't help but learn.

The thing that switched me to Macmillan was that my wife died unexpectedly of cancer, and (for the wrong reason) I had the freedom to do what I wanted to do. I ended up going to Washington (DC, USA) and doing a Master's in international policy. When I came back from that, a headhunter for Macmillan rang. If I'd been asked a couple of years before, I would have said I never wanted to hear the word cancer again, but because time had moved on, and it was Macmillan after all, seven interviews and $2.5 \mathrm{~h}$ with a psychologist later, they let me in the door.

Q Can you tell our international readers a little about Macmillan?

We're just over 100 years old, set up by a 24-year-old civil servant who watched his father die of cancer; if you can imagine what that would have been like in 1911, it wasn't a pretty thing. He was a classic kind of young entrepreneur founder. There's a lovely phrase about him that he was "often more strident than wise." He was two things; he was a bit of a campaigner - early on he was saying that smoking and tobacco were causes of cancer. He was also a bit of a 'data geek', as we'd call him today. He went to every death register in the UK and showed that there was more cancer than there used to be, incidence correlated with age, the older the population the more that you see, and that as you conquer infectious diseases, then you are going to see more of it again. For

\section{KEYWORDS}

- cancer • outcomes • prevalence

- population evidence - Macmillan

- NHS • survivorship 
much of the history of Macmillan we have been campaigning and raising awareness; we've been involved in the hospice movement, helping set up 22 hospices as independent charities.

The main points of the charity are two things. The first is improving care within the National Health Service (NHS; UK) - that is where the famous Macmillan Nurse comes in, supporting people through diagnosis, treatment and, sadly for most cancer patients, through dying. The second is making sure that the patient gets the care and support they need, not just for their cancer but for the life that comes with that; that got us into things like providing good information so that people make good decisions, ensuring financial support is in place, and in place early on.

Ultimately, Macmillan is about innovation in cancer treatment, care and support, but also being on the side of the patient and what the patient says are the priorities for them. This isn't necessarily the same as the clinical view. That's part of our role - to make sure there is a focus on the priorities of the individual and not just the measurable clinical outcome.

\section{Q Do you find there are many challenges to your work in that respect?}

Yes! Like most western health systems, we have a very medical model and we don't balance the clinical, commissioning and the patient views the right way. People tend to have binary conversations; the patient organization talk to the clinicians, the clinicians talk to the commissioner, and the commissioner talks to the patient organization, but you don't often get the three points of view in the room at the same time, having the debate. The commissioner will be trying to find out what is the most cost-effective treatment at the same time as the clinician is saying "what is the best possible from the professional point of view?" and the patient is saying "yes, that is all very well but at the same time I have this problem."

This is something we tend not to do in most developed-world health systems. We don't balance the medical model with the social model of healthcare. Until we get to that mode of operating, we're always likely to be either making decisions too focused on the money, or not enough focused on the medical or social, or not focused enough on the human being and their family. Really, it is about holding all three views in your head at the same time, which is a challenge!
Q Can you tell us about your role in NHS England?

NHS England does two things; it specifies the quality of care and it provides the money to hospitals, general practitioners (GPs) and community health centers to provide that standard of care. It is the bit of the NHS that buys healthcare on behalf of 50 million people in England. The best way to think about it is the strapline - high-quality care for all, now and for future generations. High quality speaks for itself. 'For all' means that we should provide care for everyone irrespective of who you are, what condition you have, or your ability to pay.

The 'now and for future generations' is the bit of the system where we say 'how are we going to have a national health service with an aging population with improving standards of health?'. How are we going to make the changes required so that not only do we provide high-quality care for everyone today, but also in 5, 10 or 20 years' time as well? The kind of change agenda that goes along with an aging population is part of the NHS England role. I'm one of the nine nonexecutives on that board. It's really interesting, but more than slightly scary as well!

\section{Q How do you go about predicting 20 years} in the future?

We have a GBP£100 billion budget per year. If you divide that by 50 million people, you have GBP£2000 per person, which is roughly what we spend on health in England. If you compare that with other systems - for example, the USA, which spends GBP£5000 per person and on average has a shorter life expectancy, the English system is a very efficient system. When you look where that money goes - GBP£1000 goes into local and district hospitals; GBP£500 goes into specialized hospitals; GBP£330 goes into community and mental health; and GBP£170 goes into primary care and your local GP practice. If what we're going to have is lots of people who have high morbidity, you want to have highquality care in the hospital, but you also have to get quite a lot right in the community; you have to anticipate problems, preventing their escalation. Part of the sustainability problem is that, of course, we'd like to go to the UK Treasury and say we'd like to have more than GBP£2000 per person, but we also have to say "how do we make sure we are using that GBP£2000 per person as effectively as possible?". That probably means doing more in primary and community care, 
as opposed to in the hospital; that means a big rebalancing of the system.

\section{Q Recently, you chaired the Macmillan} Question Time at the House of Commons. Can you tell our readers a little about this event? We invited members of parliament and also people living with cancer to come along and submit questions to put to our chief medical officer and the senior politicians who play a major part in cancer care. These included John Baron (Conservatives) who chairs the All-Party Parliamentary Group on Cancer, Paul Burstow, former health minister and chairman of the Liberal Democrat parliamentary party, and Andy Burnham (Labor), shadow health secretary and former secretary of state for health. It's really an opportunity for ordinary members of the public to ask questions that are of relevance to them, and for the senior politicians to hear what people are asking and worrying about.

\section{Q What do you think were the most important issues raised?}

We are not as early as some other countries in diagnosing cancer, so this is an important issue. Ways of solving this include increasing public awareness in recognizing the signs and symptoms; improving public health, such as promoting smoking cessation; and helping GPs not only identify those at high risk, but also the people who have medium relative risk.

There are also issues around uniform treatment, the postcode lottery question - you're more likely to get surgery for lung cancer if you live in one part of the country compared with the other.

We also have a serious issue here in the UK with how good we are at treating older people with cancer. We tend to be too cautious about offering treatment to people who are older; we need to move away from saying that age is a determinant of whether someone gets treatment or not, it's more about functionality. In the same way, you can have a very fit 21 -year old and a less fit one, you can have the same with 80 -year olds.

There also issues surrounding aftercare. Average survival in the UK has increased from 1 year in the 70s to approximately 6 years now and is heading up to ten years. However, that doesn't mean people are necessarily well. We know there are consequences of treatment - for example, if you had high-dose chemotherapy 20 years ago then it will have potentially done some damage to your heart; we know that women treated for breast cancer have a higher risk of a heart condition later in life. We are beginning to understand that there is a long-term condition aspect of cancer and we need to get people back to as normal a life as possible.

Another issue is patient experience - people don't tend to complain about the effectiveness of the drug or the sharpness of the scalpel, they complain about how they were treated as human beings, so dignity and respect are important. We need to give staff the time to care properly, and make sure the staff themselves operate in an environment where they are supported to give good care; we know where staff have a bad experience the patients tell us they had a bad experience too. The last point is helping people die where they want to die, which for most people is at home.

Overall, the thing we need in this country at the moment is the ambition to do something properly about cancer. It is not $\mathrm{OK}$ that the UK has some of the worst cancer outcomes of European countries given how good our system can be and how affluent the country is. We do know what good looks like and how to do it. Once we have this, all the problems become doable if we're all working together to achieve it. For me, the missing ingredient is that kind of focus and saying, as a cancer community, we are all serious about doing something and recognizing that there isn't a pile of additional cash out there to do things. We need to be smarter and more effective, finding the things that are good in one place and applying them elsewhere.

Q Macmillan also recently published its state-of-the-nation report. Can you tell us a little about the report \& the main issues it raised?

The state-of-the-nation report is a bit more comprehensive. This goes back to Macmillan being a patient-centered charity. When I started back in 2007 we had an ambition statement that said that we want to improve the lives of everyone living with cancer. What we weren't really able to say was that, like most countries even now, we couldn't tell you how many people made up 'everyone', because most health systems count the number of people diagnosed and the number who die from cancer. They don't count the number of people who die of other things. This created a problem. If we go to, let's say, Hampshire, and say "here's what we think we should do," 
no-one knew how many people there were in Hampshire with cancer, with which cancer, or how long they had it, how it was treated, or what side effects they were having 5 years later. The second problem arose when we talked about 'improve'. What would cancer patients say would improve them? We did a lot of research running up to 2010, and ended up with nine outcomes that are in that report that cancer patients say are important. What the report does is say, "how are we doing as a nation against each of those? How are we doing on early diagnosis?” Well, as mentioned earlier we need to do better on that. One of the things we need to do is to provide tools to GPs to do that. Another outcome is to treat people with dignity and respect. What are the things we can do to help the NHS have the time and the space and the tools to help patients be treated this way? It is not just a case of saying "be nicer," you have to actually do something. There are some things included such as "I want to know the people around me are supported." We hear time and time again people saying "I can cope with my cancer, but I'm worried about my partner", or their elderly parents [1].

If you had the opportunity \& the resources, what would you do in order to solve these problems?

I think the first thing I would do is say we need that ambition. Then, I would say "right, let's get some consensus across the country as to what the things we really want to be good at are". If things like early diagnosis, reducing variability, particularly for older people, looking after people once they've had their initial treatment weren't said, I'd be very surprised. The starting point for me is to get the cancer community together - the leading patients, clinical and NHS organizations - and say "look, we're not happy with the current state; can we work together to do something about it?

\section{Disclaimer}

The opinions expressed in this interview are those of the interviewee and do not necessarily reflect the views of Future Medicine Ltd.

Financial \& competing interests disclosure

$C$ Devane has no relevant affliations or financial involvement with any organization or entity with a financial interest in or financial conflict with the subject matter or materials discussed in the manuscript. This includes employment, consultancies, honoraria, stock ownership or options, expert testimony, grants or patents received or pending, or royalties.

No writing assistance was utilized in the production of this manuscript.

\section{Reference}

1 Cancer in the UK 2014. www.macmillan.org.uk 